\title{
Circumvention of Orbital Symmetry Restraints by 1,3-H-Shifts of Enolic Radical Cations
}

\author{
Charles E. Hudson and David J. McAdoo \\ Department of Neurosciences and Cell Biology, University of Texas Medical Branch, Galveston, Texas, USA
}

\begin{abstract}
The reaction coordinates of 1,3-H-shifts across double bonds are traced by theory for three reactions, $\mathrm{CH}_{3} \mathrm{C}(\mathrm{OH}) \mathrm{CH}_{2}^{+\cdot}(\mathbf{1}) \rightarrow \mathrm{CH}_{3} \mathrm{C}\left(\mathrm{O}^{+\cdot}\right) \mathrm{CH}_{3}(2), \mathrm{CH}_{2} \mathrm{C}(\mathrm{OH})_{2}^{+\cdot}(3) \rightarrow \mathrm{CH}_{3} \mathrm{CO}_{2} \mathrm{H}^{+\cdot}$ (4) and $\mathrm{CH}_{3} \mathrm{C}(\mathrm{OH}) \mathrm{CH}_{2}^{+\cdot}(\mathbf{1}) \rightarrow \mathrm{CH}_{2} \mathrm{C}(\mathrm{OH}) \mathrm{CH}_{3}^{+\cdot}\left(\mathbf{1}^{\prime}\right)$, to explore how the need to conserve orbital symmetry influences the pathways for these reactions. In the first and second reactions, prior to the start of the H-transfer the methylene rotates from being in the skeletal plane to being bisected by it. Thus these reactions are neither antarafacial nor suprafacial, but precisely between those possibilities. This stems from a counterbalancing between the need to conserve orbital symmetry and the large distorting forces required to attain an allowed antarafacial transition state. In contrast to the first two reactions, $\mathbf{1} \rightarrow \mathbf{1}^{\prime}$ follows a suprafacial pathway. However, this pathway does not violate conservation of orbital symmetry, as it utilizes lower lying orbitals of appropriate symmetry rather than the antisymmetric uppermost occupied allyl-type orbital. Changes in geometry which presumably produce asymmetric vibrational excitation and the unequal losses of methyl that follow $\mathbf{1} \rightarrow \mathbf{2}$, i.e., nonergodic behavior, are also characterized. (J Am Soc Mass Spectrom 2004, 15, 972-981) (c) 2004 American Society for Mass Spectrometry
\end{abstract}

$\mathrm{I}$ $\mathrm{n}$ their classic review of the role of the conservation of orbital symmetry in chemical reactions, Woodward and Hoffmann concluded that suprafacial 1,3-H-shifts across double bonds are unlikely to occur because such reactions would not conserve orbital symmetry [1]. They also predicted that antarafacial 1,3-Hshifts would be suppressed by the high energy required to form transition states containing small, twisted rings. Nonetheless 1,3-H-shifts do occur [2-17], or would were it not for competition from lower energy processes [18-23]. Theoretical studies conducted since the work of Woodward and Hoffmann show that 1,3-H-shifts across $\pi$-bonds can be antarafacial $[19,20,22]$, suprafacial [22], or at the boundary between the two such that they are neither antarafacial nor suprafacial [22], a surprising diversity of trajectories.

$\mathrm{CH}_{2} \mathrm{CHOH}^{+\cdot} \rightarrow \mathrm{CH}_{3} \mathrm{CHO}^{+\cdot}$ would have an in-between transition state, should that reaction occur [22]. Interestingly, the first evidence for such an in between pathway was obtained by applying semi-empirical theory [14] to a reaction, degenerate isomerization of the acetone enolate, which instead has an antarafacial transition state according to a later ab initio study [23]. The 1,3-H-shift $\mathrm{CH}_{3} \mathrm{C}(\mathrm{OH}) \mathrm{CH}_{2}^{+*}(\mathbf{1}) \rightarrow \mathrm{CH}_{3} \mathrm{C}\left(=\mathrm{O}^{+\cdot}\right) \mathrm{CH}_{3}$ (2) (Scheme 1) has been characterized by experiment $[2,3$,

Published online June 19, 2004

Address reprint requests to Professor D. J. McAdoo, Department of Neurosciences and Cell Biology, University of Texas Medical Branch, 301 University Blvd., Galveston, TX 77555-1043, USA. E-mail: djmcadoo@ utmb.edu
5-10, 13], by ab initio [12] and density functional [17] theories, and by trajectory analysis [17]. Atoms in $\mathbf{1}$ are labeled throughout this contribution as indicated in the following formula.<smiles>[CH2]C(C)=[OH+]</smiles>

Although $\mathbf{1} \rightarrow \mathbf{2}$ appears symmetry forbidden [8, 10] because the highest (singly) occupied orbital should be antisymmetric with respect to the skeletal plane in $\mathbf{1}$ and symmetric in 2, the atomic trajectories and molecular orbitals utilized during that reaction have not been considered in relation to the need to preserve orbital symmetry. Therefore to explore further the origin of the variety of transition states that mediate 1,3-H-shifts and their relationships to conservation of orbital symmetry, we used theory to characterize the isomerizations of $\mathbf{1}$ and $\mathrm{CH}_{2} \mathrm{C}(\mathrm{OH})_{2}^{+\cdot}(3)$ (Scheme 2) $[4,11]$ to their carbonyl isomers and the nearly degenerate $1,3-\mathrm{H}$-shift between the terminal carbons of $\mathbf{1}$ [3]. The enol $\rightarrow$ keto conversions actually occur but the keto $\rightarrow$ enol conversions do not because the reverse rearrangements are not competitive with CC dissociation. This work has its origins in the McLafferty group [2,3,10], so we offer it in honor of 
<smiles>CC(C)=[OH+]</smiles><smiles>CC1C[IH]O1</smiles>

1

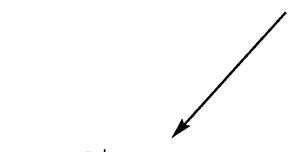<smiles>CCC(C)=[OH+]</smiles>

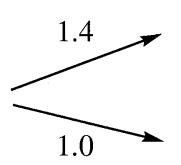

$\mathrm{CH}_{3} \mathrm{CO}^{+}+{ }^{-} \mathrm{CH}_{2} \mathrm{H}^{\mathrm{t}}$

$\cdot \mathrm{CH}_{3}+{ }^{+} \mathrm{OCCH}_{2} \mathrm{H}^{\mathrm{t}}$

2

Scheme 1

Fred's distinguished contributions to mass spectrometry and the American Society for Mass Spectrometry, and to his still amazing productivity in his 80th year.

The course of $\mathbf{1} \rightarrow \mathbf{2}$ is of special interest because the newly formed methyl is lost 1.4 times more often than the pre-existing one, i.e., isomerization is followed by non-ergodic dissociation [2, 3, 5-10, 12, 13, 17]. These dynamics arise in a substantially deeper well than in other systems known to display such behavior, enhancing the significance of $\mathbf{1} \rightarrow \mathbf{2}$ [17]. Excitation of $\mathrm{CCO}$ bond bending by the isomerization appears to play a role in nonergodic dissociation following $\mathbf{1} \rightarrow \mathbf{2}[13,17]$, but one-sided excitation of other motions may also contribute. Thus we also characterize changes in geometry during $\mathbf{1} \rightarrow \mathbf{2}$ to increase insight into how these motions may contribute to the unequal losses of methyl.

\section{Results and Discussion}

In the following, we will consider a reaction to be antarafacial if in the vicinity of the transition state the migrating $\mathrm{H}$ crosses the skeletal plane, suprafacial if the migrating $\mathrm{H}$ remains on the same side of that plane throughout the reaction and in between if it remains in the plane throughout the reaction. A reaction will be considered allowed if in the H-transfer orbital lobes of the same phase overlap and forbidden if lobes of opposite phase interact, as illustrated in Figure 1.

Energies obtained by theory for pertinent stationary points on the $\mathrm{C}_{3} \mathrm{H}_{6} \mathrm{O}^{+\cdot}$ potential surface are given in Table 1 . The energies obtained for the transition state for $\mathbf{1} \rightarrow 2,178-201 \mathrm{~kJ} \mathrm{~mol}^{-1}$ above $\Delta_{\mathrm{f}} \mathrm{H}(\mathbf{1})$, are all higher than the $165 \mathrm{~kJ} \mathrm{~mol}^{-1}\{(\mathrm{MP} 3 / 6-31 \mathrm{G}(\mathrm{d}, \mathrm{p})$ theory $\}$ of Schwarz, Lifshitz and coworkers [12], and higher still than the B3LYP/cc-pVTZ energy of Numella and Carpenter [17], $143 \mathrm{~kJ} \mathrm{~mol}^{-1}$ when corrected by our zero point energies. Experimental values range from $193 \mathrm{~kJ}$ $\mathrm{mol}^{-1}$ to $253 \mathrm{~kJ} \mathrm{~mol}^{-1}[5,7,9,24]$. The UHF wave functions of the transition states obtained by QCISD/6$31 G(d, p)$ theories have high $s^{2}$ values in both the

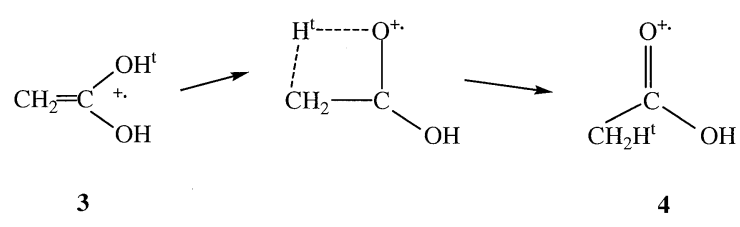

Scheme 2

6-31G(d,p) and 6-311G(d,p) basis sets (see Theory), indicating substantial spin contamination. However this did not dramatically affect the energies obtained, as projecting out spin contamination did not substantially affect those energies (Tables 1 and 2). The lower threshold usually obtained by theory than by experiment supports experimental evidence for a significant kinetic shift in $\mathbf{1} \rightarrow \mathbf{2}$ [13]. A kinetic shift is an increase in the measured threshold for a fragmentation in a mass spectrometer relative to the actual threshold; it is caused by the reaction being too slow at its true threshold to give measurable products.

Geometries of $\mathbf{1}, \mathbf{2}$, and $\operatorname{TS}(\mathbf{1} \rightarrow \mathbf{2})$ obtained by QCISD/6-31G(d,p) theory are given in Figure 2, and the changes in dihedral angles involving $\mathrm{H}^{\mathrm{t}}$ and the methylene hydrogens over the course of the reaction are plotted as a function of $\mathrm{OH}$ distance in Figure 3. The $\mathrm{OH}$ distance was selected as the independent variable because it reflects the course of the reaction as $\mathrm{H}_{t}$ moves from $\mathrm{O}$ to $\mathrm{C}$. All of the atoms of $\mathbf{1}$ except two of the methyl hydrogens are in the same plane, and the latter are symmetrically located on opposite sides of that plane $\left( \pm 121.5^{\circ}\right)$. The geometry of 2 has $C_{2}$ symmetry with the methyls rotated about $3^{\circ}$ in opposite directions from the skeletal plane. The $\mathrm{CH}$ bonds near the skeletal plane both point in the same direction as the oxygen in 2 (Figure 2c). In TS (1 $\rightarrow 2$ ), the spectator methyl is also bisected by the skeletal plane, with $\mathrm{H}^{\mathrm{t}}$ in the skeletal plane. $\mathrm{H}^{\mathrm{t}}$ stays within $0.6^{\circ}$ of the skeletal plane throughout the isomerization, and does not leave that plane after $\mathrm{RO}-\mathrm{H}_{\mathrm{t}}$ has increased more than $0.01 \AA$ from its values in $\mathbf{1}$ (Figure 3a). According to intrinsic reaction coordinate (IRC) tracing (Figure 3), starting from 1 the methylene rotates $90^{\circ}$ from being in the skeletal plane to

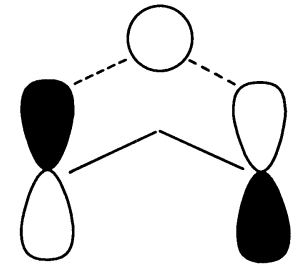

Forbidden (suprafacial)

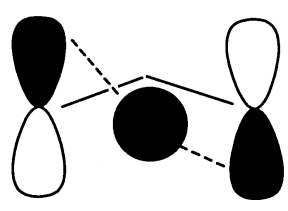

Allowed (antarafacial)
Figure 1. Transition states for suprafacial and antarafacial 1,3-Hshifts across a $\pi$-bond. In the surprafacial case, the phase of the lobe on the carbon being departed differs from the phase on the destination carbon, making the reaction forbidden. In the antarafacial pathway, the phases of the involved lobes are of the same sign, a symmetry which allows the reaction. The solid angled lines represent the $\sigma \mathrm{CC}$ bonds in the skeletal plane. 
Table 1. Ab initio energies for pertinent stationary point on the $\mathrm{C}_{3} \mathrm{H}_{6} \mathrm{O}^{+\cdot}$ potential surface

\begin{tabular}{|c|c|c|c|c|c|}
\hline & $\mathrm{B} 3 \mathrm{LYP} / 6-31 \mathrm{G}(\mathrm{d})^{\mathrm{a}}$ & QCISD/6-31G $(d, p)^{b}$ & $\operatorname{QCISD}(T) / 6-311 \mathrm{G}(\mathrm{d}, \mathrm{p})^{\mathrm{b}}$ & PMP3/6-31G $(d, p)^{b}$ & PMP3/6-311G $(d, p)^{b}$ \\
\hline $\mathrm{CH}_{3} \mathrm{C}(\mathrm{OH}) \mathrm{CH}_{2}^{+\cdot}(\mathbf{1})$ & -192.820301 & -192.282263 & -192.374322 & -192.271585 & -192.342766 \\
\hline $\mathrm{CH}_{2} \mathrm{C}(\mathrm{OH}) \mathrm{CH}_{3}^{+\cdot}\left(1^{\prime}\right)^{\mathrm{c}}$ & -192.822543 & -192.284198 & -192.376137 & & \\
\hline $\mathrm{TS}(\mathbf{1} \rightarrow \mathbf{2})$ & -192.746462 & -192.201623 & -192.299183 & -192.188945 & -192.261710 \\
\hline $\mathrm{CH}_{3} \mathrm{C}\left(=\mathrm{O}^{+} \cdot \mathrm{CH}_{3}(2)\right.$ & -192.811279 & -192.269802 & -192.363749 & -192.254542 & -192.327267 \\
\hline $\mathrm{TS}\left(1 \rightarrow 1^{\prime}\right)$ & -192.731516 & -192.191126 & -192.290385 & -192.184137 & -192.260278 \\
\hline $\mathrm{CH}_{3} \mathrm{C}(\mathrm{OH}) \mathrm{CH}_{2}^{+\cdot}(\mathbf{1})$ & 0 & 0 & 0 & 0 & 0 \\
\hline $\mathrm{CH}_{2} \mathrm{C}(\mathrm{OH}) \mathrm{CH}_{3}^{+\cdot}\left(1^{\prime}\right)^{\mathrm{c}}$ & -5.3 & -5.7 & -5.4 & & \\
\hline $\mathrm{TS}(\mathbf{1} \rightarrow \mathbf{2})$ & 178 & 195 & 181 & 201 & 196 \\
\hline $\mathrm{CH}_{3} \mathrm{C}\left(=\mathrm{O}^{+}\right) \mathrm{CH}_{3}(2)$ & 19 & 28 & 23 & 40 & 36 \\
\hline $\mathrm{TS}\left(1 \rightarrow 1^{\prime}\right)$ & 218 & 224 & 205 & 214 & 201 \\
\hline
\end{tabular}

Energies in the upper portion of the table are in hartrees, and those in the lower part are in $\mathrm{kJ} \mathrm{mol}^{-1}$.

aEnergy calculated for a B3LYP/6-31G(d) geometry.

bEnergy calculated for a QCISD/6-31g(d,p) geometry.

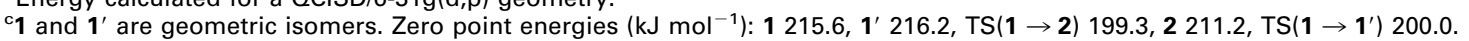

being bisected by it during an increase of only $0.013 \AA$ in the $\mathrm{OH}$ bond length (Figure $3 b$ ).

Thus, as in the interconversion of the acetaldehyde radical cation and its enol [22], rotation and $\mathrm{H}$-transfer are separate stages in $\mathbf{1} \rightarrow \mathbf{2}$, that is, rotation precedes $\mathrm{H}$-transfer. The energy needed to reach the transition state from $\mathbf{1}$ is roughly equally divided between that required to rotate $\mathrm{CH}_{2}\left(106 \mathrm{~kJ} \mathrm{~mol}^{-1}\right.$ to reach symmetry at $\mathrm{HCCO}= \pm 96.6^{\circ}$ in the IRC calculations) and that it then takes to transfer the hydrogen to reach the transition state (an additional $88 \mathrm{~kJ} \mathrm{~mol}^{-1}$ ).

Previous workers suggested that distortion of the CCO bonds immediately following $\mathbf{1} \rightarrow \mathbf{2}$ contributes to the unequal losses of the methyls $[13,17]$. The geometry of $\mathrm{TS}(\mathbf{1} \rightarrow \mathbf{2})$ relative to that of $\mathbf{2}$ potentially provides further insight into the origin of the methyl loss pattern, so bond lengths and angles at those stationary points are compared in Table 3 . The $\mathrm{C} 3 \mathrm{C} 2 \mathrm{O}$ angle, that is, the angle involving the pre-existing methyl, changes from $125.4^{\circ}$ to $119.0^{\circ}$, so distortion of this angle may contribute to the unequal losses of methyl. However, the C1C2O angle changes much more substantially (by $21.2^{\circ}$ ) in the course of $\mathbf{1} \rightarrow \mathbf{2}$, suggesting that this makes a greater contribution to the preferential loss of the newly formed methyl. The HCC bond angles involving the methylene hydrogens change considerably between $\mathbf{1}$ and 2, although changes in the lengths of the associated $\mathrm{CH}$ bonds are small. RC2C3 increases only $0.016 \AA$ more than does RC1C2 between the transition state and 2 , a difference unlikely to contribute significantly to the asymmetry of the energy distribution in newly formed 2. Bond lengths in the pre-existing methyl change little, and the HCC bond angles in that methyl change substantially less than those in the conversion of methylene to methyl. Thus, as would be expected, distortions, and therefore probably immediate energy deposition, in the newly formed methyl are substantially greater than in the pre-existing methyl following $\mathbf{1} \rightarrow \mathbf{2}$, consistent with this deposition causing preferential loss of the newly created methyl. However, differences occurring in Table 3 are for a minimum energy pathway; energized species have different trajectories [17], likely akin to those that would directly connect the geometries in Table 3.

To relate molecular orbital utilization to the need to conserve orbital symmetry, population analysis was used to obtain the coefficients at each atom of the atomic orbitals used to generate the molecular orbitals.

Table 2. Ab initio energies for pertinent stationary point on the $\mathrm{C}_{2} \mathrm{H}_{4} \mathrm{O}_{2}^{+\cdot}$ potential surface

\begin{tabular}{|c|c|c|c|c|c|}
\hline & B3LYP/6-31G(d) ${ }^{a}$ & QCISD/6-31G $(d, p)^{b}$ & $\operatorname{OCISD}(T) / 6-311 \mathrm{G}(\mathrm{d}, \mathrm{p})^{\mathrm{b}}$ & PMP3/6-31G(d,p) & PMP3/6-311G(d,p) \\
\hline $\mathrm{CH}_{2} \mathrm{C}(\mathrm{OH})_{2}^{+\cdot}(3)^{\mathrm{c}}$ & -228.730800 & -228.136859 & -228.255641 & -228.125016 & -228.221818 \\
\hline $\mathrm{TS}(3 \rightarrow 4 a)^{d}$ & -228.654181 & -228.052250 & -228.177107 & -228.038505 & -228.137331 \\
\hline $\mathrm{TS}(\mathbf{3} \rightarrow \mathbf{4 b})^{\mathrm{e}}$ & -228.650100 & -228.048067 & -228.173196 & -228.034350 & -228.133498 \\
\hline $\mathrm{CH}_{3} \mathrm{CO}_{2} \mathrm{H}^{+\cdot}(4 \mathbf{a})^{\mathrm{d}}$ & -228.704971 & -228.107132 & -228.225919 & -228.093179 & -228.190245 \\
\hline $\mathrm{CH}_{3} \mathrm{CO}_{2} \mathrm{H}^{+\cdot}(\mathbf{4 b})^{\mathrm{e}}$ & -228.701183 & -228.103862 & -228.222900 & -228.090885 & -228.188408 \\
\hline $\mathrm{CH}_{2} \mathrm{C}(\mathrm{OH})_{2}^{+\cdot}(3)^{\mathrm{c}}$ & 0 & 0 & 0 & 0 & 0 \\
\hline $\mathrm{TS}(3 \rightarrow 4 a)^{d}$ & 186 & 207 & 191 & 200 & 207 \\
\hline $\mathrm{TS}(\mathbf{3} \rightarrow \mathbf{4 b})^{\mathrm{e}}$ & 197 & 218 & 202 & 211 & 217 \\
\hline $\mathrm{CH}_{3} \mathrm{CO}_{2} \mathrm{H}^{+\cdot}(4 \mathbf{a})^{\mathrm{b}}$ & 64 & 74 & 74 & 68 & 79 \\
\hline $\mathrm{CH}_{3} \mathrm{CO}_{2} \mathrm{H}^{+\cdot}(\mathbf{4 b})^{\mathrm{e}}$ & 75 & 84 & 83 & 75 & 85 \\
\hline
\end{tabular}

Energies in the upper portion of the table are in hartrees, and those in the lower part are in $\mathrm{kJ} \mathrm{mol}^{-1}$.

aEnergy calculated for a B3LYP/6-31G(d) geometry.

bEnergy calculated for a QCISD/6-31g(d,p) geometry.

${ }^{\mathrm{c}}$ The $\mathrm{OH}$ bonds point in opposite directions (see Fig. 3a).

${ }^{\mathrm{d}}$ The spectator $\mathrm{H}$ on $\mathrm{O}$ points in the same direction as the other $\mathrm{O}$ (see Fig. $3 \mathrm{~b}$ ); these are the species occurring in the pathway considered.

${ }^{e} \mathrm{OH}$ points in the other $\mathrm{O}$ (see Fig. 3c). Zero point energies (kJ mol${ }^{-1}$ ) 3 157.7, TS(3 $\rightarrow$ 4a) 142.6, TS(3 $\rightarrow$ 4b) 142.9, 4a 153.9, 4b 154.9. 


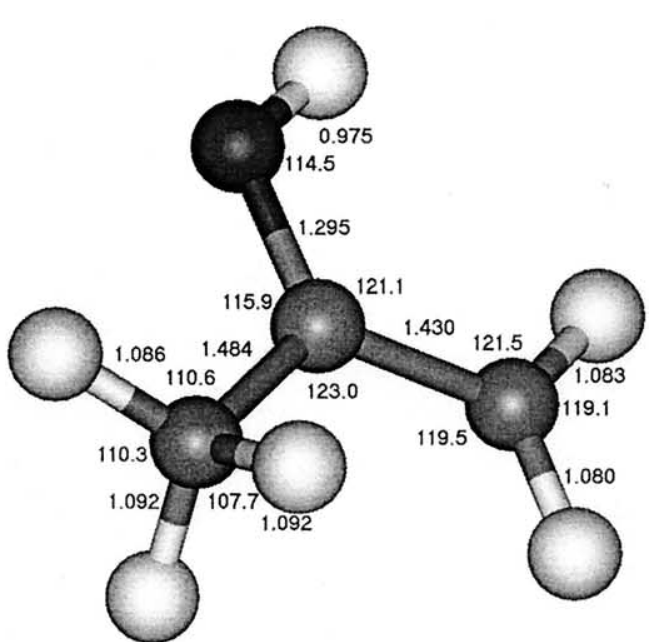

1
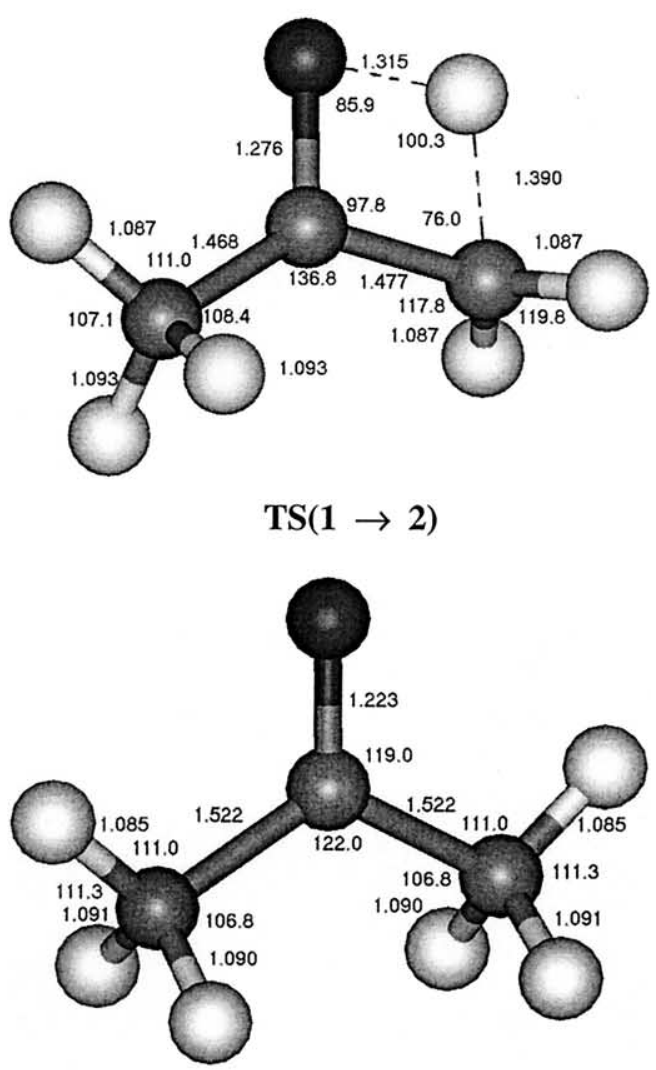

2

Figure 2. Geometries of $\mathrm{CH}_{3} \mathrm{C}(\mathrm{OH}) \mathrm{CH}_{2}^{+\cdot}$ (1) (a), $\mathrm{CH}_{3} \mathrm{C}(\mathrm{O}) \mathrm{CH}_{3}^{+\cdot}$ (2) (c), and TS $(\mathbf{1} \rightarrow \mathbf{2})(\mathbf{b})$ at the QCISD/6-31G(d,p) level of theory.

Four orbitals were found to participate significantly in bonding in the transition state: $\alpha 13, \beta 13, \beta 15$, and $\alpha 16$, the last two being the highest occupied $\beta$ and $\alpha$ orbitals respectively. In these calculations, each electron is treated as occupying its own spin orbital, hence electrons of a pair are in orbitals designated $\alpha$ and $\beta$ with the same number specifying their energy level starting with the lowest lying level designated as 1 . Phase and electron density at pertinent atoms at the transition state for $\mathbf{1} \rightarrow \mathbf{2}$, as obtained by the population analysis, are given in Table 4. Degree of bonding can be assessed by inspection of the values in the table. Allowance must be made for the y components being most important in $\mathrm{H}^{\mathrm{t}} \mathrm{O}$ bonding as $\mathrm{H}_{t}$ is predominantly in the y direction from O. Similarly, $x$ components dominate the $\mathrm{H}^{\mathrm{t} C}$ interaction. Based on this, orbitals $\alpha 13$ and $\beta 13$ are bonding in both the $\mathrm{H}^{\mathrm{t}} \mathrm{O}$ and the $\mathrm{H}^{\mathrm{t}} \mathrm{C}$ bonds, $\beta 15$ is strongly bonding in $\mathrm{H}^{\mathrm{t}} \mathrm{O}$ and antibonding in $\mathrm{H}^{\mathrm{t}} \mathrm{C}$ (weakly because the large coefficients are for y components), and $\alpha 16$ is strongly bonding in $\mathrm{H}^{\mathrm{t}} \mathrm{C}$ but strongly antibonding in $\mathrm{H}^{\mathrm{t}} \mathrm{O}$. To objectively classify the bonding to $\mathrm{H}^{\mathrm{t}}$, the $\mathrm{x}$ and $\mathrm{y}$ components on $\mathrm{C}$ and $\mathrm{O}$ were multiplied by the $\mathrm{S}$ components on $\mathrm{H}^{\mathrm{t}}$ and the results for the $\mathrm{x}$ and $\mathrm{y}$ components separately summed. For $\mathrm{H}^{\mathrm{t}} \mathrm{C}$, these sums were 0.33 and -0.14 for the $\mathrm{x}$ and $\mathrm{y}$ components, respectively, and for the $\mathrm{H}^{\mathrm{t}} \mathrm{O}$ interactions -0.01 and 0.08 . Thus in the transition state the $\mathrm{H}^{\mathrm{t}} \mathrm{C}$ bond is strong and the $\mathrm{H}_{\mathrm{t}} \mathrm{O}$ bond is weak, but both interactions are bonding. The overlap populations separately provided by these calculations, 0.37 and 0.19 , respectively, demonstrate significant bonding between $\mathrm{H}^{\mathrm{t}}$ and both carbon and oxygen at this transition state. There were no orbitals resembling an allyl $\pi$-orbital in $\mathrm{TS}(\mathbf{1} \rightarrow \mathbf{2})$, supporting the disappearance of $\pi$-bonding upon rotation of $\mathrm{CH}_{2}$ in this transition state.

\section{$3 \rightarrow 4$}

We also characterized $3 \rightarrow 4$ to define further the prevalence of $1,3-\mathrm{H}$-shifts in $\mathrm{CHRC}(\mathrm{OH}) \mathrm{R}^{+\cdot}$ species $(\mathrm{R}$ $=\mathrm{H}$, an alkyl, $\mathrm{OH}$, etc.) by methylene rotation- $-\mathrm{H}-$ transfer. Energies for the relevant stationary points on the $\mathrm{C}_{2} \mathrm{H}_{4} \mathrm{O}_{2}^{+\cdot}$ potential surface are given in Table 2 , and the geometries at those points are given in Figure 4 . The structures of 3 and 4 are unexceptional, both being planar except two of the methyl hydrogens of the latter are outside of and symmetrical to the skeletal plane. Based on $\mathrm{OH}$ orientations, 3 can have three possible geometric isomers, although $\mathrm{H}$-transfer to $\mathrm{CH}_{2}$ requires an $\mathrm{OH}$ to be oriented toward that $\mathrm{CH}_{2}$. However, past experience indicates that the most stable protonated carboxyl configurations have the $\mathrm{OH}^{\prime}$ s pointed in opposite directions, as illustrated in Figure 4a (Hudson and McAdoo, unpublished). TS( $3 \rightarrow 4)$ and 4 can have the non-reacting $\mathrm{OH}$ oriented toward or away from the methyl. The energies for both possible transition states are given in Table 2, although only the transition state with the stationary $\mathrm{H}$ away from the developing methyl (Figure $4 b$ ) is directly accessible from the ground state geometry considered. Energies for both isomers of 4 are also given, although only 4 a (Figure 4 c) would form by the pathway considered. As in $\operatorname{TS}(\mathbf{1} \rightarrow \mathbf{2})$, high s ${ }^{2}$ values were obtained for QCISD results (see Theory). However, projecting these out did not substantially alter the transition state energies obtained (Table 2). The critical energy for $\mathbf{3} \rightarrow \mathbf{4 a}, 186-210 \mathrm{~kJ} \mathrm{~mol}^{-1}$, is similar to the $178-201 \mathrm{~kJ} \mathrm{~mol}^{-1}$ obtained for $\mathbf{1} \rightarrow \mathbf{2}$ at corresponding levels of theory. 

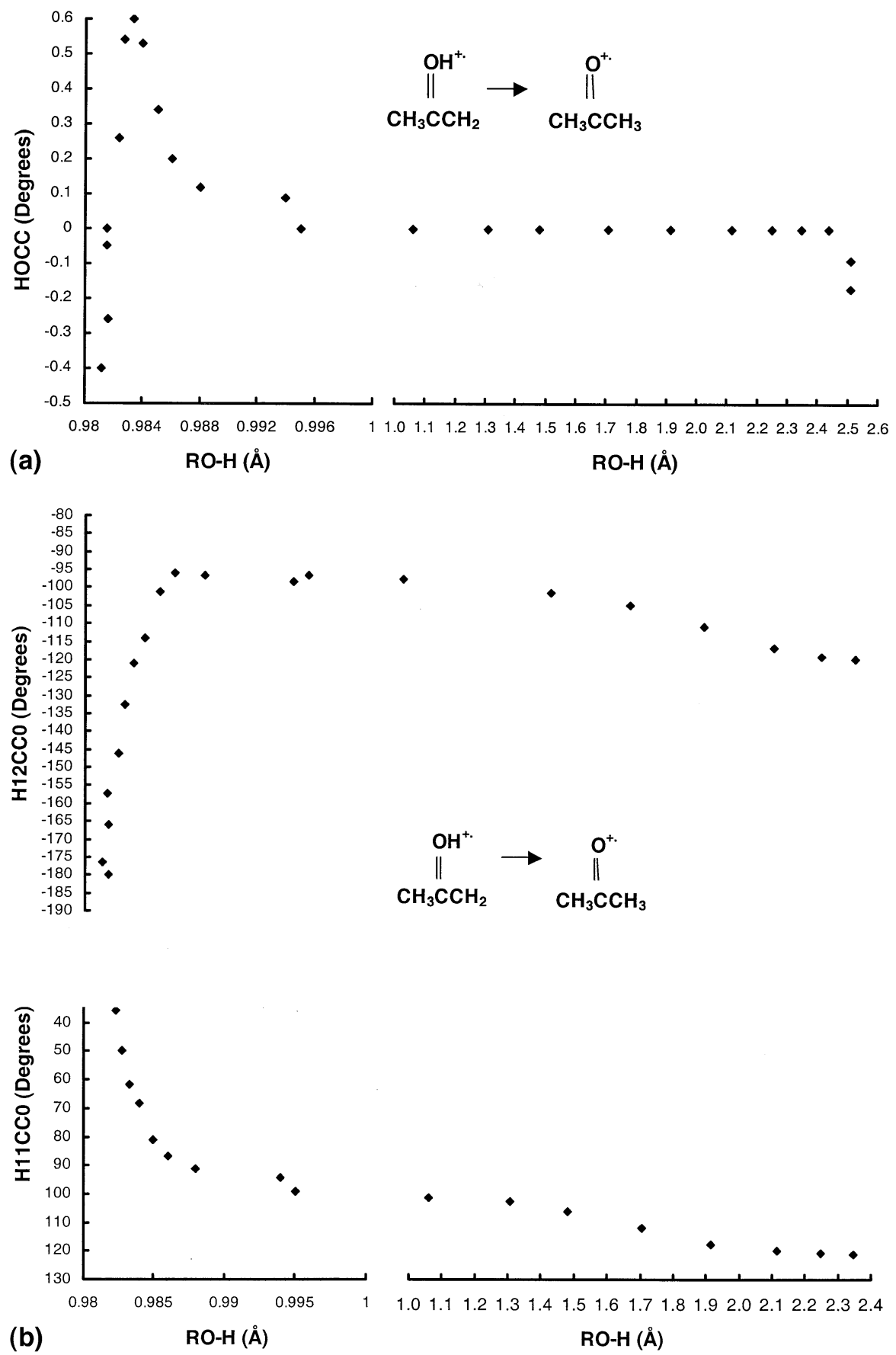

Figure 3. Changes as a function of $\mathrm{OH}$ distance in (a) the $\mathrm{H}^{\mathrm{t}} \mathrm{OC} 2 \mathrm{C} 1$ dihedral angle and (b) in the $\mathrm{HC} 1 \mathrm{C} 2 \mathrm{O}$ dihedral angle for the methylene hydrogens during the course of $\mathbf{1} \rightarrow \mathbf{2}$. The data for the plots were obtained by IRC calculations. Note that the scale of the X-axes is greatly expanded to the left of the breaks in them. $H_{t}$ remains in the skeletal plane throughout the reaction, while the methylene rotates from its hydrogens being in the plane to being symmetrically bisected by the plane during a change of less than $0.01 \AA$ in the $\mathrm{OH}$ bond length.

In the IRC for $3 \rightarrow 4, \mathrm{H}^{\mathrm{t}}$ starts in the $\mathrm{CCO}$ plane and deviates maximally from it by $3.0^{\circ}\left(\mathrm{CCOH}_{\mathrm{t}}\right.$ dihedral angle) over the course of the reaction. $\mathrm{H}_{\mathrm{t}}$ moves in and out of the plane before it starts to transfer (Figure 5a). Thus this excursion is irrelevant to the classification of the reaction as antarafacial or suprafacial. The two methylene hydrogens are in the skeletal plane of 3
( $\mathrm{HCCO}$ dihedral angles of 0.00 and $180.0^{\circ}$ ) and turn to $120.3^{\circ}$ and $-120.3^{\circ}$ from the CCO plane in the methyl in 4 (Figure 5b). Starting from 3, the methylene hydrogens become symmetric to the plane $\left(91.1^{\circ}\right.$ and $\left.-91.1^{\circ}\right)$ as the $\mathrm{OH}$ distance increases from only $0.9784 \AA$ to $0.9814 \AA$, that is, well before the transition state $(\mathrm{OH}$ distance $=$ $1.326 \AA$ ) is attained. Thus this $1,3-\mathrm{H}$-shift also twists the 
Table 3. QCISD/6-31G $(\mathrm{d}, \mathrm{p})$ geometries for $\mathrm{TS}(\mathbf{1} \rightarrow \mathbf{2})$ and $\mathrm{CH}_{3} \mathrm{C}\left(\mathrm{O}^{+\cdot}\right) \mathrm{CH}_{3}$

\begin{tabular}{lcc}
\hline Parameter & Transition state & $\mathrm{CH}_{3} \mathrm{C}\left(\mathrm{O}^{+\cdot}\right) \mathrm{CH}_{3}$ \\
\hline \hline Bond lengths (in $\AA$ ) & & \\
$\mathrm{ROH}_{\mathrm{t}}$ & 1.315 & 2.506 \\
$\mathrm{RCH}_{\mathrm{t}}$ & 1.389 & 1.085 \\
$\mathrm{RC} 1 \mathrm{C} 2$ & 1.477 & 1.522 \\
$\mathrm{RC2C} 3$ & 1.468 & 1.522 \\
$\mathrm{RCH} 11$ & 1.087 & 1.091 \\
$\mathrm{RCH} 12$ & 1.087 & 1.090 \\
$\mathrm{RCH31}$ & 1.087 & 1.030 \\
$\mathrm{RCH} 32$ & 1.093 & 1.085 \\
$\mathrm{Bond}$ angles (in degrees) & & \\
$\mathrm{CCC}$ & 136.8 & 122.0 \\
$\mathrm{C} 1 \mathrm{C} 2 \mathrm{O}$ & 97.8 & 119.0 \\
$\mathrm{C} 3 \mathrm{C} 2 \mathrm{O}$ & 125.4 & 119.0 \\
$\mathrm{CCH}$ & & 111.0 \\
$\mathrm{H} 11 \mathrm{CC}$ & 76.0 & 106.4 \\
$\mathrm{H} 12 \mathrm{CC}$ & 117.8 & 106.7 \\
$\mathrm{H} 31 \mathrm{CC}$ & 117.8 & 106.8 \\
$\mathrm{H} 32 \mathrm{CC}$ & 111.0 & 111.0 \\
$\mathrm{RCH33}$ & 108.4 & 1.091 \\
$\mathrm{H} 33 \mathrm{CC}$ & 1.093 & 106.4 \\
\hline
\end{tabular}

plane of its methylene to being perpendicular to the skeletal plane before starting to transfer $H_{t}$ in the skeletal plane. Since this occurs in all keto-enol isomerizations examined to date (present results and reference [22]), it appears to be general for such isomerizations.

Ions and corresponding neutrals can differ in the trajectories of their 1,3-H-shifts, as the 1,3-H-shift that would convert vinyl alcohol to acetaldehyde proceeds suprafacially without methylene being twisted to anywhere near $90^{\circ}$ while in the ion the methylene is twisted until it is bisected by the skeletal plane [22]. Presumably the removal of one electron from the $\pi$-systems in the radical cations lowers the energy required to rotate the methylene, while the higher energy required for this rotation in $\mathrm{CH}_{2}-\mathrm{CHOH}$ [22] probably forces $\mathrm{CH}_{2}=\mathrm{CHOH} \rightarrow \mathrm{CH}_{3} \mathrm{CHO}$ to be suprafacial.

$1 \rightarrow 1^{\prime}$

To extend our knowledge of the reaction coordinates for 1,3-H-shifts, we also characterized the degenerate isomerization $\mathbf{1} \rightarrow \mathbf{1}^{\prime}$, another known 1,3-H-shift [3].

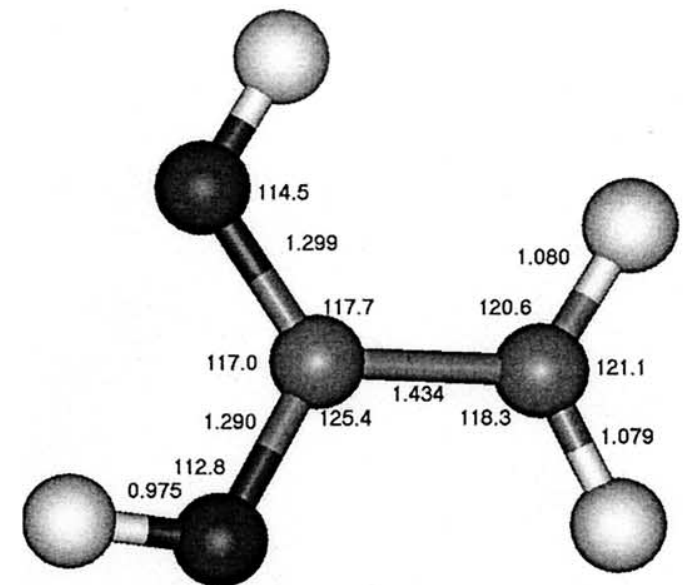

3

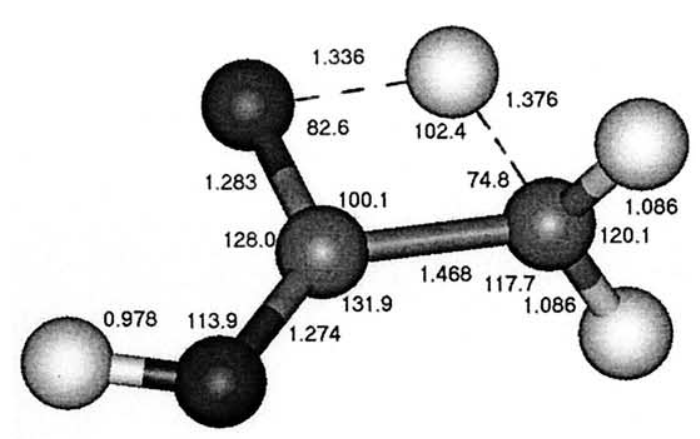

$\mathrm{TS}(3 \rightarrow 4)$

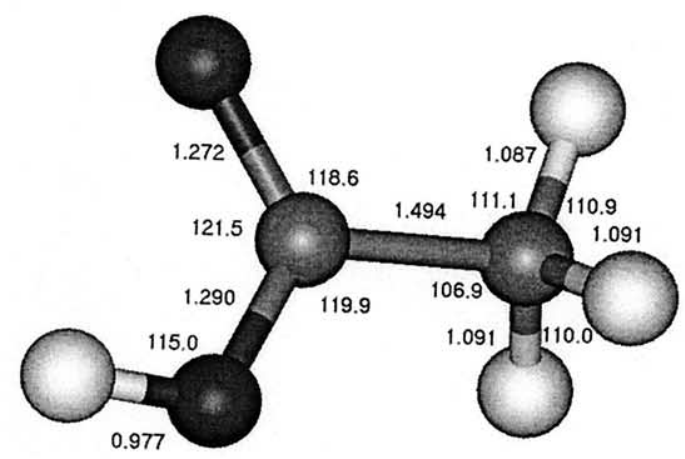

4

Figure 4. Geometries of $\mathrm{CH}_{2} \mathrm{C}(\mathrm{OH})_{2}^{+\cdot}$ (3) (a), $\mathrm{CH}_{3} \mathrm{CO}_{2} \mathrm{H}^{+\cdot}$ (4) (c), and TS $(3 \rightarrow 4)(b)$ at the QCISD/6-31G $(\mathrm{d}, \mathrm{p})$ level of theory.

Table 4. Molecular orbital coefficients in the transition state for $\mathrm{CH}_{3} \mathrm{C}(\mathrm{OH}) \mathrm{CH}_{2}^{+\cdot} \rightarrow \mathrm{CH}_{3} \mathrm{C}(\mathrm{O}) \mathrm{CH}_{3}^{+\cdot}$

\begin{tabular}{|c|c|c|c|c|c|c|c|c|c|c|}
\hline \multirow[b]{2}{*}{ Orbital } & \multicolumn{10}{|c|}{ Components } \\
\hline & $\mathrm{H} 1 \mathrm{~S}$ & $\mathrm{H} 2 \mathrm{~S}$ & $02 P_{x}$ & $\mathrm{O}_{2} \mathrm{P}_{\mathrm{y}}$ & $\mathrm{O} \mathrm{P}_{\mathrm{x}}$ & $\mathrm{O}^{2} \mathrm{P}_{\mathrm{y}}$ & $\mathrm{C} 2 \mathrm{P}_{\mathrm{x}}$ & $\mathrm{C} 2 \mathrm{P}_{\mathrm{y}}$ & $\mathrm{C} \mathrm{P}_{\mathrm{x}}$ & $\mathrm{C} 3 \mathrm{P}_{\mathrm{y}}$ \\
\hline Alpha 13 & 0.14 & 0.12 & -0.01 & 0.21 & 0.01 & 0.13 & 0.08 & -0.14 & 0.06 & -0.06 \\
\hline Beta 13 & 0.13 & 0.11 & -0.05 & 0.20 & -0.01 & 0.13 & 0.09 & -0.03 & 0.06 & -0.01 \\
\hline Beta 15 & -0.18 & -0.16 & -0.23 & -0.18 & -0.16 & -0.13 & -0.02 & 0.31 & -0.03 & 0.16 \\
\hline Alpha 16 & 0.14 & 0.14 & -0.23 & -0.39 & -0.15 & -0.28 & 0.47 & -0.13 & 0.35 & -0.08 \\
\hline
\end{tabular}

Analyses were performed with B3LYP/6-31G(d) theory. Tabulated values reflect the coefficients representing the contribution of the indicated component to the overall orbital. Like signs of values on atoms reflect bonding interactions and unlike signs anti-bonding interactions. The signs of the $x$ and $y$ components on oxygen in the program output have been reversed to take into account the location of the other atoms being considered in negative $x$ and $y$ directions from the oxygen. Numbers preceding $S$ and $P$ are levels of the component orbital. The carbon is $C 1$ according to the numbering scheme utilized throughout this work. 

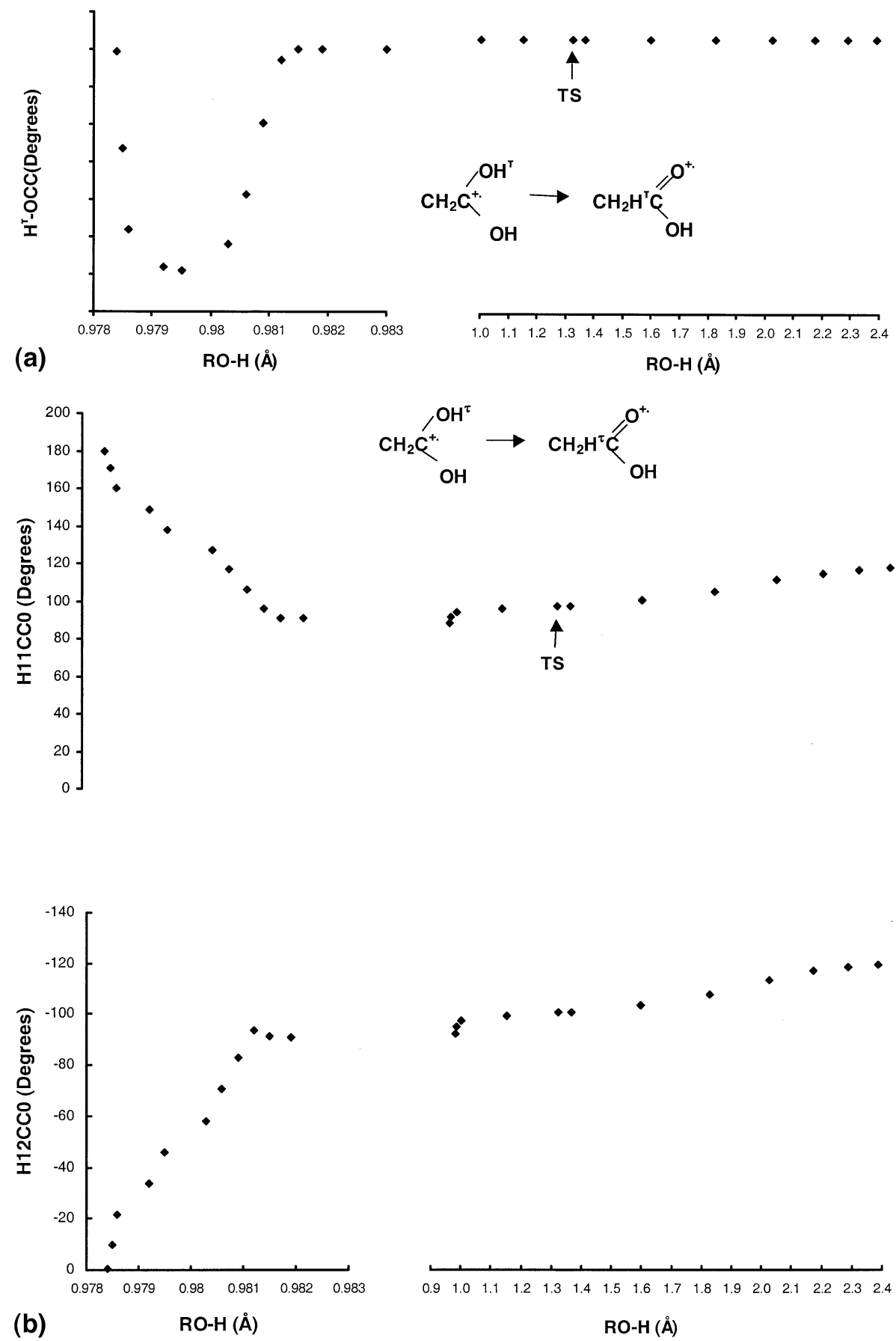

Figure 5. IRC changes in the $\mathrm{CCOH}^{t}$ dihedral angle (a) and $\mathrm{HCCO}$ dihedral angles (b) for the methylene hydrogens (H11 and H12) as a function of $\mathrm{OH}$ distance during the course of $3 \rightarrow 4$. Note that the $\mathrm{X}$ axis is expanded nearly 200fold in the left portion of the figures, and that except for a very brief 3 degree excursion during the first $0.0035 \AA$ of the extension of $\mathrm{ROH}^{\mathrm{t}}, \mathrm{H}^{\mathrm{t}}$ remains in the skeletal plane throughout the reaction.

The energy of this transition state, $201-224 \mathrm{~kJ} \mathrm{~mol}^{-1}$ (Table 1), is slightly higher than that for $\mathbf{1} \rightarrow \mathbf{2}$. The geometry of $\operatorname{TS}\left(\mathbf{1} \rightarrow \mathbf{1}^{\prime}\right)$ is given in Figure 6 . At the transition state, $H_{t}$ is above the skeletal plane and essentially equidistant $(1.5726 \AA$ and $1.5776 \AA$ ) between $\mathrm{C} 1$ and $\mathrm{C} 3$. At that point, $\mathrm{H}^{\mathrm{t}}$ is closer to the middle $(1.3361 \AA)$ than to the terminal carbons in $\operatorname{TS}\left(\mathbf{1} \rightarrow \mathbf{1}^{\prime}\right)$, indicating bonding between $\mathrm{H}^{\mathrm{t}}$ and $\mathrm{C} 2$. TS $\left(\mathbf{1} \rightarrow \mathbf{1}^{\prime}\right)$ is close to $\mathrm{C}_{\mathrm{s}}$ symmetry, the $\mathrm{CH}_{2}$ groups being nearly in the same plane, a plane which is rotated $20^{\circ}-23.5^{\circ}$ from the skeletal plane. IRC tracing (Figure 7a) yielded the very surprising observation that $\mathrm{H}^{t}$ stays on the same side of the skeletal plane throughout $\mathbf{1} \rightarrow \mathbf{1}^{\prime}$, i.e., this is clearly a suprafacial 1,3-shift, in contrast to the two 


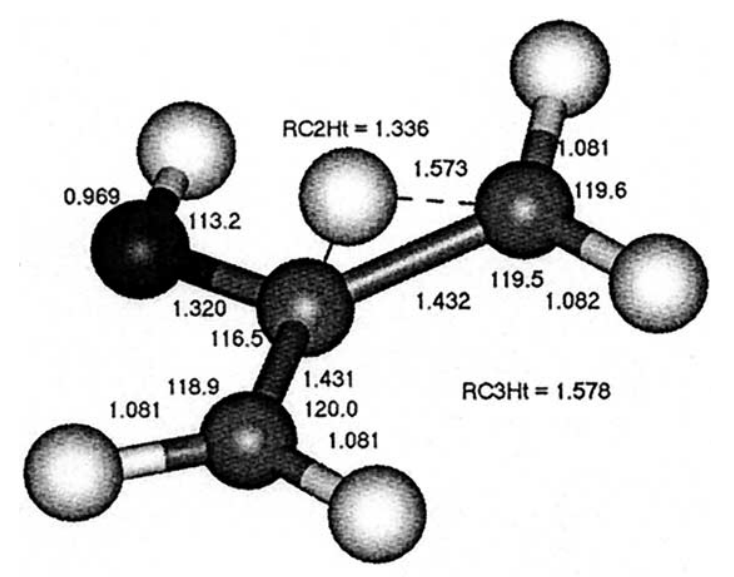

\section{$\operatorname{TS}\left(1 \rightarrow 1^{\prime}\right)$}

Figure 6. Transition state geometry from $\mathrm{QCISD} / 6-31 \mathrm{G}(\mathrm{d}, \mathrm{p})$ theory for the degenerate interconversion of $\mathrm{CH}_{3} \mathrm{C}(\mathrm{OH}) \mathrm{CH}_{2}^{+\cdot}$ with itself. In this picture, $\mathrm{H}^{\mathrm{t}}$ is above the skeletal plane and equidistant between $\mathrm{C} 1$ and $\mathrm{C} 3$.

reactions described above. In $\mathbf{1} \rightarrow \mathbf{1}^{\prime}, \mathrm{H}$ simply migrates above the plane from the methyl to the methylene with the incipient methylene flattening as it forms while the developing methyl assumes a tetrahedral geometry. The methyl existing at the beginning and end of $\mathrm{H}$ transfer rotates about $15^{\circ}$ near those endpoints to leave or attain the equilibrium geometry of $\mathbf{1}$ (Figure $7 \mathrm{~b}$ ). The energies of the starting and ending points differ because the structure at one point is a geometric isomer of that at the other.

We characterized the molecular orbitals involved in $\mathbf{1} \rightarrow \mathbf{1}^{\prime}$ to assess the possibility that this reaction violates conservation of orbital symmetry. Atomic orbital coefficients generated for the molecular orbitals by population analysis and signs of the phases of their interactions with those at $\mathrm{H}_{t}$ are given in Table 5. This analysis revealed that, as would be expected for an allylic system, the highest (singly) occupied MO (orbital 16) in $\operatorname{TS}\left(\mathbf{1} \rightarrow \mathbf{1}^{\prime}\right)$ has its positive lobe on the first carbon and its negative lobe on the third carbon pointing in the same direction from the CCC plane. Therefore, if suprafacial $\mathrm{H}$-transfer utilizes primarily the highest singly occupied molecular orbital, $\mathrm{H}$ transfer would involve lobes of opposite phase, violating conservation of orbital symmetry. However, such a violation does not occur because $\mathrm{H}$ transfer essentially does not involve those lobes as there is very little density on $\mathrm{H}_{\mathrm{t}}$ in this orbital; thus the transfer avoids utilizing orbital 16 in which $\mathrm{H}$ transfer would utilize lobes on the carbons of opposite phase. Instead the H-transfer uses lower lying orbitals (orbitals $9 \alpha$ and $\beta, 11 \alpha$ and $\beta$, and $15 \alpha$ and $\beta$, numbered in order of increasing energy) and interacts significantly with the middle carbon to accomplish a suprafacial 1,3-shift without violating orbital symmetry. Based on phase relationships, orbitals $9 \alpha$ and $\beta$ contribute substantially to bonding between $\mathrm{H}^{\mathrm{t}}$ and all

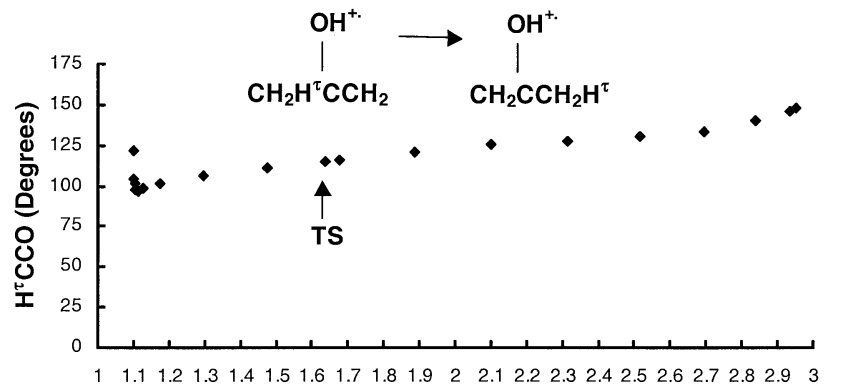

(a)

RC3-H $(\AA)$
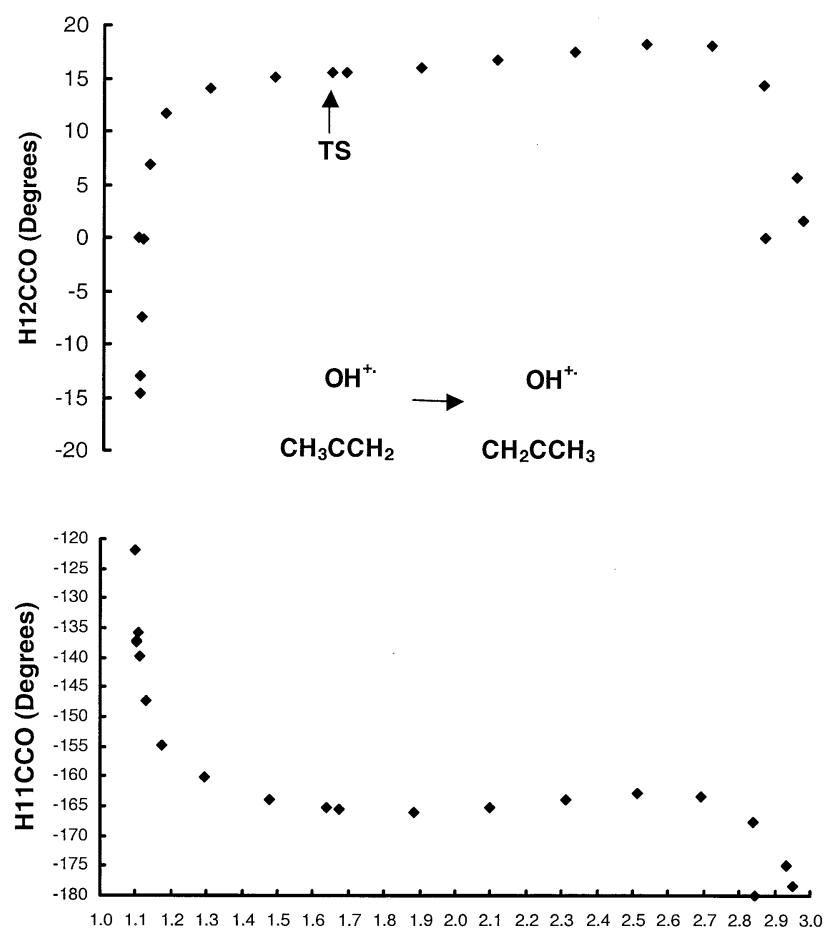

(b)

$\mathrm{RC}-\mathrm{H}_{\mathrm{t}}(\AA)$

Figure 7. IRC tracing of the $\mathrm{H}^{\mathrm{t}} \mathrm{C} 3 \mathrm{C} 2 \mathrm{O}$ dihedral angle (a) and the HCCO dihedral angles (b) for the two hydrogens that change from being methyl to being methylene hydrogens during the course of $\mathbf{1} \rightarrow \mathbf{1}^{\prime}$. Note that $\mathrm{H}_{t}$ starts, stays and ends above the skeletal plane during the reaction. Methyl and methylene hydrogens revolve only to the degree necessary to change their positions in one of those groups to their positions in the other during the course of the reaction.

three carbons; orbital 11 contributes slightly to net bonding between $\mathrm{H}^{\mathrm{t}}$ and $\mathrm{C} 1$ and $\mathrm{H}^{\mathrm{t}}$ and $\mathrm{C} 3$, and substantially to bonding between $\mathrm{H}^{\mathrm{t}}$ and $\mathrm{C} 2 . \alpha$ and $\beta$ orbitals 15 contribute significantly to bonding between $\mathrm{H}^{\mathrm{t}}$ and both $\mathrm{C} 1$ and $\mathrm{C} 3$ and little or nothing to bonding between $\mathrm{H}^{\mathrm{t}}$ and $\mathrm{C} 2$. Use of lower lying orbitals with appropriate phase relationships is thus another way that symmetry constraints on 1,3-H-shifts across $\pi$-bonds are circumvented. Use of a subjacent allyl type orbital to avoid orbital symmetry constraints on use of frontier orbitals was first proposed about 30 years ago [25-28], and it has been suggested that involvement of subjacent orbitals may be particularly important in the chemistry of radical cations [29]. 
Table 5. Molecular orbital coefficients in the transition state for $\mathrm{CH}_{3} \mathrm{C}(\mathrm{OH}) \mathrm{CH}_{2}^{+\cdot} \rightarrow \mathrm{CH}_{2} \mathrm{C}(\mathrm{OH}) \mathrm{CH}_{3}^{+\cdot}$

\begin{tabular}{|c|c|c|c|c|c|c|c|c|c|c|c|}
\hline \multirow[b]{2}{*}{ Orbital } & \multirow[b]{2}{*}{$\mathrm{H} 1 \mathrm{~S}$} & \multirow[b]{2}{*}{$\mathrm{H} 2 \mathrm{~S}$} & \multicolumn{9}{|c|}{ Components } \\
\hline & & & $\mathrm{C} 12 \mathrm{P}_{\mathrm{x}}$ & $\mathrm{C} 12 \mathrm{P}_{\mathrm{y}}$ & $\mathrm{C} 12 \mathrm{P}_{\mathrm{z}}$ & $\mathrm{C} 22 \mathrm{P}_{\mathrm{x}}$ & $\mathrm{C} 22 \mathrm{P}_{\mathrm{y}}$ & $\mathrm{C} 22 \mathrm{P}_{\mathrm{z}}$ & $\mathrm{C} 32 \mathrm{P}_{\mathrm{x}}$ & $\mathrm{C} 32 \mathrm{P}_{\mathrm{y}}$ & $\mathrm{C} 32 \mathrm{P}_{\mathrm{z}}$ \\
\hline Alpha 9 & -0.14 & -0.06 & -0.24 & -0.12 & -0.04 & 0.035 & -0.21 & -0.13 & -0.18 & -0.05 & -0.04 \\
\hline Beta 9 & -0.14 & -0.07 & -0.23 & -0.13 & -0.02 & 0.03 & -0.19 & -0.12 & -0.17 & -0.04 & -0.02 \\
\hline Alpha 11 & 0.13 & 0.11 & -0.17 & 0.08 & 0.19 & -0.01 & -0.06 & 0.32 & -0.11 & -0.10 & 0.18 \\
\hline Beta 11 & 0.13 & 0.11 & -0.17 & 0.07 & 0.15 & 0.00 & -0.06 & 0.33 & -0.10 & -0.11 & 0.36 \\
\hline Alpha 15 & -0.16 & -0.20 & 0.01 & 0.05 & -0.20 & 0.01 & 0.06 & -0.04 & 0.04 & -0.03 & -0.17 \\
\hline Beta 15 & -0.21 & -0.27 & 0.03 & 0.06 & -0.15 & 0.02 & 0.07 & -0.10 & 0.06 & -0.03 & -0.14 \\
\hline Alpha 16 & 0.01 & 0.02 & -0.08 & 0.06 & -0.43 & -0.02 & 0.00 & 0.01 & 0.05 & 0.08 & 0.44 \\
\hline
\end{tabular}

Values and interactions are as described in the footnote to Table 4. Numbers following the Cs are the designations of the carbons used throughout this work.

Whether conservation of orbital symmetry is important in the chemistry of open shell species is sometimes questioned. A number of 1,3-H-shifts in radical cations have now been characterized by theory, and all of those circumvent pathways that violate conservation of orbital symmetry [19, 20, 22]. Some of those expend substantial energy to take symmetry-allowed pathways through antarafacial transition states [19], some have transition states at the boundary between being antarafacial and suprafacial (present results), and some utilize subjacent orbitals to take suprafacial pathways (present results). Thus, as in closed shell species, these reactions do not violate conservation of orbital symmetry. Therefore, orbital symmetry is usually conserved in the reactions of both open and closed shell species.

\section{Theory}

All calculations were performed by unrestricted theories using the Gaussian 98W package of programs [30]. Geometries were obtained by B3LYP/6-31G(d) hybrid functional and QCISD/6-31G(d,p) ab initio theories. B3LYP/6-31G(d), QCISD/6-31G(d,p), and QCISD(T)/6$311 \mathrm{G}(\mathrm{d}, \mathrm{p})$ theories were used to obtain energies for stationary points. Zero point energies were obtained by multiplying B3LYP/6-31G(d) frequencies by the scaling factor 0.9806 [31]. Transition states were all characterized by having only one imaginary frequency. $\mathrm{S}^{2}$ values were very close to 0.75 for ground states and B3LYP transition states, but in the vicinity of 0.81 for QCISD results (UHF theory) for $\mathrm{TS}(\mathbf{1} \rightarrow \mathbf{2})$ and $\mathrm{TS}(\mathbf{3} \rightarrow \mathbf{4})$ and 0.86 for TS $\left(\mathbf{1} \rightarrow \mathbf{1}^{\prime}\right)$. Projecting out the contributions of states $\mathrm{s}+1$ to $\mathrm{s}+4$ with PMP3 calculations gave $\mathrm{s}^{2}$ values of 0.7500 for all stationary points at their QCISD/6-31G $(d, p)$ geometries. This raised the energy of 2 and most of the transition states by $10-20 \mathrm{~kJ} \mathrm{~mol}^{-1}$ (Tables 1 and 2). A multi-configuration treatment was necessary for characterizing the 1,3-H-shift in propene [32]. To determine whether such theory is required to obtain reliable results for the 1,3-H-shifts characterized here, we characterized $\operatorname{TS}(\mathbf{1} \rightarrow \mathbf{2})$ and $\operatorname{TS}\left(\mathbf{1} \rightarrow \mathbf{1}^{\prime}\right)$ by complete active space $\{5,5 / 6-31 \mathrm{G}(\mathrm{d})$ theory $\}$ and compared the geometries obtained to those obtained by UHF/6-31G(d) theory. Deviations between values in the Z-matrices for $\operatorname{TS}\left(\mathbf{1} \rightarrow \mathbf{1}^{\prime}\right)$ from the two theories were $0.0012 \pm 0.008 \AA, 0.19 \pm 0.4$ degrees and $0.33 \pm 1.0$ degrees for bond lengths, bond angles and dihedral angles respectively ( \pm s.d.). We did not obtain relative energies by the complete active space approach because optimization of $\mathbf{1}$ failed at this level of theory. Nonetheless, the close similarities of the geometries obtained by the two levels of theory indicate that multi-configuration methods are not needed to adequately characterize the reaction coordinates studied here. Reaction trajectories were characterized by intrinsic reaction coordinate (IRC) methods $[33,34]$ utilizing B3LYP/6-31G(d) theory. Interactions between atoms were classified as bonding or antibonding based on atomic orbital coefficients obtained by population analysis, also using B3LYP/6-31G(d) theory. Overlapping phases with like signs on adjacent atoms were taken as indicating bonding, and interacting phases of opposite signs were taken to reflect antibonding.

\section{Acknowledgments}

The authors thank Debbie Pavlu, Bhavin Shah, and Jason Dunsmore for help with manuscript preparation.

\section{References}

1. Woodward, R. B.; Hoffmann, R. The Conservation of Orbital Symmetry. Angew. Chem. Int. Ed. 1969, 8, 781-852.

2. McAdoo, D. J.; McLafferty, F. W.; Smith, J. S. Ketonization of Gaseous Enol ions. J. Am. Chem. Soc. 1970, 92, 6343-6345.

3. McLafferty, F. W.; McAdoo, D. J.; Smith, J. S.; Kornfeld, R. The Enolic $\mathrm{C}_{3} \mathrm{H}_{6} \mathrm{O}^{+}$Ion Formed from Aliphatic Ketones. J. Am. Chem. Soc. 1971, 93, 3720-3730.

4. Griffin, L. L.; McAdoo, D. J. Decompositions of the Metastable $\left[\mathrm{CH}_{2} \mathrm{C}(\mathrm{OH})_{2}\right]^{+\cdot}$ ion. A Test of the Applicability of the Energy Randomization Hypothesis to Unimolecular Fragmentations. J. Phys. Chem. 1979, 83, 1142-1144.

5. Lifshitz, C.; Tzidony, E. Kinetic Energy Release Distribution for $\mathrm{C}_{3} \mathrm{H}_{6} \mathrm{O}^{+\cdot}$ Ion Dissociations: A Further Test of the Applicability of the Energy-Randomization Hypothesis to Unimolecular Fragmentations. Int. J. Mass Spectrom. Ion Phys. 1981, 39, 181-195.

6. Lifshitz, C. A Surprisal Analysis of the Dissociation Dynamics of $\mathrm{C}_{3} \mathrm{H}_{6} \mathrm{O}^{+\cdot}$ Cations. Int. J. Mass Spectrom. Ion Phys. 1982, 43, 179-193. 
7. Lifshitz, C.; Berger, P.; Tzidony, E. Kinetic Energy Release Distributions (KERDs) for the Dissociation of Metastable Ions. Chem. Phys. Lett. 1983, 95, 109-113.

8. Lifshitz, C. Intramolecular Energy Redistribution in Polyatomic Ions. J. Phys. Chem. 1983, 87, 2304-2313.

9. Tureček, F.; Hanuš, V. Loss of Methyl from $\left[\mathrm{H}_{2} \mathrm{C}=\mathrm{C}(\mathrm{OH})\right.$ $\left.\mathrm{CH}_{3}\right]^{+\cdot}$ Ions Prepared by Electron-Impact Ionization of Unstable 2-Hydroxypropene. Org. Mass Spectrom. 1984, 19, 631-638.

10. Tureček, F.; McLafferty, F. W. Non-Ergodic Behavior in Acetone-Enol Ion Dissociations. J. Am. Chem. Soc. 1984, 106, 2525-2528.

11. Heinrich, N.; Schwarz, H. On the Role of Ion/Dipole Complexes in the Isomerization/Dissociation Reactions of Ionized Acetic Acid and Its Enol in the Gas Phase. An ab Initio Molecular Orbital Study. Int. J. Mass Spectrom. Ion Processes 1987, 79, 295-310.

12. Heinrich, N.; Louage, F.; Lifshitz, C.; Schwarz, H. Competing Reactions of the Acetone Cation Radical: RRKM-QET Calculations on an ab Initio Potential Energy Surface. J. Am. Chem. Soc. 1988, 110, 8183-8192.

13. Osterheld, T. H.; Brauman, J. I. Infrared Multiple-Photon Dissociation of the Acetone Enol Radical Cation. Dependence of Nonstatistical Dissociation on Internal Energy. J. Am. Chem. Soc. 1993, 115, 10311-10316.

14. Sannes, K. A.; Brauman, J. I. 1,3-Hydrogen Rearrangements of Vibrationally Activated Enolate Ions in the Gas Phase. J. Am. Chem. Soc. 1995, 117, 10088-10092.

15. Hudson, C. E.; McAdoo, D. J. Isomerization of $\mathrm{CH}_{3} \mathrm{O}^{+}=\mathrm{CHCH}_{3}$ to $\mathrm{CH}_{2}=\mathrm{O}^{+} \mathrm{CH}_{2} \mathrm{CH}_{3}$. J. Am. Soc. Mass Spectrom. 1998, 9, 130-137.

16. McAdoo, D. J. Contributions of $\mathrm{C}_{3} \mathrm{H}_{6} \mathrm{O}^{+\cdot}$ Ions with the Oxygen on the Middle Carbon to Gas Phase Ion Chemistry. Mass Spectrom. Rev. 2000, 19, 38-61.

17. Nummela, J. A.; Carpenter, B. K. Nonstatistical Dynamics in Deep Potential Wells: A Quasiclassical Trajectory Study of Methyl Loss from the Acetone Radical Cation. J. Am. Chem. Soc. 2002, 124, 8512-8513.

18. Apeloig, Y.; Karni, M.; Ciommer, B.; Depke, G.; Frenking, G.; Meyn, S.; Schmidt, J.; Schwarz, H. Mechanism of Keto-Enol Tautomerism of Ionized Vinyl Alcohol Versus Acetaldehyde and Their Dissociation to $\mathrm{C}_{2} \mathrm{H}_{3} \mathrm{O}^{+}$and $\mathrm{H}$. An ab Initio Molecular Orbital Study. Int. J. Mass Spectrom. Ion Processes 1984, 59, 21-37.

19. Nguyen, M. T.; Landuyt, L.; Vanquickenborne, L. G. 1,3Hydrogen Shift in Propene Radical Cation: A Facile Antarafacial Rearrangement. Chem. Phys. Lett 1991, 182, 225-231.

20. Houk, K. N.; Li, Y.; Evanseck, J. D. Transition structures of hydrocarbon pericyclic reactions. Angew. Chem. Int. Ed. 1992, 31, 682-708.

21. Bertrand, W.; Bouchoux, G. Keto-Enol Tautomerism and Dissociation of Ionized Acetaldehyde and Vinyl Alcohol. A G2
Molecular Orbital Study. Rapid Commun. Mass Spectrom. 1998, 12, 1697-1700.

22. Hudson, C. E.; McAdoo, D. J. 1,3-H-Shift Pathways in $\mathrm{C}_{2} \mathrm{H}_{4} \mathrm{O}^{++}$ and $\mathrm{C}_{2} \mathrm{H}_{4} \mathrm{O}$. Int. J. Mass Spectrom. 2002, 219, 295-303.

23. Hudson, C. E.; McAdoo, D. J. An ab Initio Study of Substituent Effects in [1,3]-hydrogen shifts. J. Org. Chem. 2003, 68, 27352740.

24. McAdoo, D. J.; McLafferty, F. W.; Parks, T. E. Isomerization and Decomposition Reactions of $\mathrm{C}_{4} \mathrm{H}_{8} \mathrm{O}^{+}$ions ${ }^{1-3}$. J. Am. Chem. Soc. 1972, 94, 1601-1609.

25. Berson, J. A.; Salem, L. Subjacent Orbital Control. An Electronic Factor Favoring Concertedness in Woodward-Hoffmann "Forbidden" Reactions. J. Am. Chem. Soc. 1972, 94, 8917-8918.

26. Berson, J. A. Orbital-Symmetry Forbidden Reactions. Accts. Chem. Res. 1972, 5, 406-414.

27. Epiotis, N. D.; Yates, R. L.; Bernardi, F. Substituent Effects on Subjacent Orbital Control. J. Am. Chem. Soc. 1975, 97, 41984202.

28. Bouma, W. J.; Vincent, M. A.; Radom, L. Ab Initio Molecular Orbital Studies of Sigmatropic Rearrangements. Int. J. Quant. Chem. 1978, 14, 767-777.

29. Haselbach, E.; Bally, T.; Lanyiova, Z. Studies on Radical Cations. II. Principles Involved in Their Electrocyclic Reactions. Helv. Chem. Acta 1979, 62, 577-582.

30. Frisch, M. J.; Trucks, G. W.; Schlegel, H. B.; Scuseria, G. E.; Robb, M. A.; Cheeseman, J. R.; Zakrzewski, V. G.; Montgomery, J. A., Jr.; Stratmann, R. E.; Burant, J. C.; Dapprich, S.; Millam, J. M.; Daniels, A. D.; Kudin, K. N.; Strain, M. ; Farkus, O.; Tomasi, J.; Barone, V.; Cossi, M.; Cammi, R.; Mennucci, B.; Pomelli, C.; Adamo, C.; Clifford, S.; Ochterski, J.; Petersson, G. A.; Ayala, P. Y.; Cui, Q.; Morokuma, K.; Malick, D. K.; Rabuck, A. D.; Raghavachari, K.; Foresman, J. B.; Cioslowski, J.; Ortiz, J. V.; Baboul, A. G.; Stefanov, B. B.; Liu, G.; Liashenko, A.; Piskorz, P.; Komaromi, I.; Gomperts, R.; Martin, R. L.; Fox, D. J.; Keith, T.; Al-Laham, M. A.; Peng, C. Y.; Nanayakkara, A.; Challacombe, M.; Gill, P. M. W.; Johnson, B.; Chen, W.; Wong, M. W.; Andres, J. L.; Gonzalez, C.; Head-Gordon, M.; Replogle, E. S.; Pople, J. A. Gaussian 98; Gaussian, Inc.: Pittsburgh, PA, 1998.

31. Scott, A. P.; Radom, L. Harmonic Vibrational Frequencies: An Evaluation of Hartree-Fock, Moller-Plesset, Quadratic Configuration Interaction, Density Functional Theory, and Semiempirical Scale Factors. J. Phys. Chem. 1996, 100, 16502-16513.

32. Bernardi, F.; Robb, M. A.; Schlegel, H. B.; Tomachini, G. An MC-SCF Study of [1,3] and [1,2] Sigmatropic Shifts in Propene. J. Am. Chem. Soc. 1984, 106, 1198-1202.

33. Gonzalez, C.; Schlegel, H. B. An Improved Algorithm for Reaction Path Following. J. Chem. Phys. 1989, 90, 2154-2161.

34. Gonzalez, C.; Schlegel, H. B. Reaction Path Following in Mass-Weighted Internal Coordinates. J. Phys. Chem. 1990, 94, 5523-5527. 